\title{
Atividades Maker no Processo de Criação de Projetos por Estudantes do Ensino Básico para uma Feira de Ciências
}

\author{
André L. A. Raabe ${ }^{12}$, André L. M. Santana ${ }^{1}$, Luís F. M. Santana ${ }^{1}$, Marli F. Vick \\ Vieira $^{12}$, Julia Peron Metzger ${ }^{1}$, Eduardo Borges Gomes ${ }^{1}$ \\ ${ }^{1}$ Laboratório de Inoavação Tecnológica na Educação (LITE) \\ ${ }^{2}$ Programa de Pós-Graduação em Educação \\ Universidade do Vale de Itajaí (UNIVALI) \\ Itajaí - SC - Brazil \\ \{raabe@univali.br, andrelms@univali.br\}
}

\begin{abstract}
The article reports and presents reflections about the potential of maker activities for learning and developing computational thinking concepts. We conducted an extension project inspired by constructionist tenants with 12 (twelve) high school students of a public school and 2 (two) volunteers student from a private school. The paper details the process of creation using different technologies and emphasizes the last activity focused on creating artifacts for the school Science Fair. The makers activities are reported in this article followed by some reflections supported by the records of observations in the field. The results indicate that makers activities developed in constructionist environments stimulate creativity, inventiveness, collaboration, sharing of ideas and information that make the students protagonists in the development of their own knowledge, not favoring gender or social difference.
\end{abstract}

Resumo. $O$ artigo relata e promove uma reflexão acerca da aprendizagem e do potencial de atividades maker ("mão na massa") para o desenvolvimento do pensamento computacional. Um projeto de extensão inspirado em pressupostos construcionistas foi realizado com 12 estudantes do ensino médio de uma escola estadual e 2 (dois) alunos voluntários de escolas particulares do município de Itajaí. $O$ artigo relata a criação dos projetos utilizando diferentes tecnologias e enfatiza um atividade voltada a criação de artefatos a serem apresentados na feira de ciências da escola. As atividades makers são relatadas nesse artigo seguidas de reflexões apoiadas nos registros e nas observações realizadas em campo. Os resultados indicam que atividades makers em ambientes construcionistas estimulam a criatividade, a inventividade, a colaboração, o compartilhamento de ideias e de informações que possibilitam tornar os participantes protagonistas no desenvolvimento de sua própria aprendizagem, não privilegiando gênero nem diferença de contexto social. 
V Congresso Brasileiro de Informática na Educação (CBIE 2016)

Anais do XXII Workshop de Informática na Escola (WIE 2016)

\section{Introdução}

A humanidade com o objetivo de aprimorar habilidades cognitivas desenvolve tecnologias que podem estimular, de forma criativa, a aprendizagem. A abordagem construcionista (PAPERT, 1980) instiga habilidades e competências por meio de atividades em que o aprendiz, por meio do fazer, coloca a mão na massa construindo algo de seu interesse e para o qual está motivado. Por meio de procedimentos, o protagonista desse processo, aprende a resolver problemas em aspectos distintos de sua vida.

A cultura maker, de colocar a mão na massa, está associada com práticas presentes na Ciência da Computação. Um indivíduo "maker" combina tecnologia, conhecimento e computação e suas ações são motivadas para concretizar projetos específicos (MILNE; RIECKE; ANTLE, 2014). O movimento maker está relacionado à aprendizagem prática no qual o estudante é protagonista do processo de construção do seu conhecimento, aprendendo assuntos de seu interesse e satisfação. $\mathrm{Na}$ aprendizagem prática ocorre a valorização da experiência do educando, permitindo que esse aprenda com seus erros e acertos, com a satisfação em compreender assuntos e temas do seu próprio interesse, que estão relacionados com seu cotidiano (BLIKSTEIN, 2013).

$\mathrm{O}$ aprendiz passa a atuar como autor do próprio ambiente de aprendizado, de forma descentralizada passa a produzir seu próprio material didático e ajuda os demais colegas na resolução dos problemas apresentados. Ideias que estão sendo relacionadas ao termo Pensamento Computacional que proporciona aprender de maneira criativa, no qual $\mathrm{o}$ modelo de troca de conhecimento entre mediador e estudante deixa de ser somente expositivo (BLIKSTEIN, 2009).

O termo Pensamento Computacional cunhado por Janette Wing em 2006, apresentase como "uma maneira de resolver os problemas, conceber sistemas e compreender o comportamento humano que se baseia em conceitos fundamentais da Ciência da Computação" (NRC, 2010, p.10). As competências contidas nesse termo podem ser utilizadas para estimular a capacidade de resolução de problemas em qualquer área do conhecimento e em qualquer fase da vida, explorando a criatividade e a construção do saber.

Santana (2015, p.31) identifica o pensamento computacional como o "desenvolvimento de habilidades que favorecem a resolução de problemas, em que através da organização do modo de pensar, é possível expandir a capacidade mental, permitindo resolver os mais diversos níveis de desafio". A aprendizagem pratica e o pensamento computacional convergem para um ensino que prioriza a criatividade, inventividade $\mathrm{e}$ produtividade dos alunos, que são protagonistas no desenvolvimento do seu próprio conhecimento.

O projeto relatado nessa experiência visa promover o pensamento computacional de forma criativa em um ambiente construcionista, que se baseia no aprendizado prático com raízes na cultura maker, oportunizando a cada individuo criar sua própria tecnologia seguindo seus interesses. O ambiente Maker que essa experiência foi realizada é o Laboratório de Inovação Tecnológica na Educação - Lite. 
V Congresso Brasileiro de Informática na Educação (CBIE 2016)

Anais do XXII Workshop de Informática na Escola (WIE 2016)

\section{Materiais e Métodos}

O Lite é um laboratório de ensino e pesquisa que realiza também projetos de extensão. O laboratório passou nos últimos dois anos a modificar sua atuação, anteriormente mais voltada ao desenvolvimento de software, para adotar e fomentar a cultura maker nos projetos desenvolvidos pelos seus integrantes e voluntários. Desde então o ambiente vem sendo transformado a partir de uma reorganização dos móveis existentes buscando proporcionar um espaço de fomento ao trabalho em grupo e a colaboração. Estações com computadores passaram a co-habitar o espaço com estações de marcenaria e eletrônica. Novos equipamentos que potencializem a prototipação rápida, como a impressora 3D, e que auxiliam nos projetos foram incluídos no ambiente, de acordo com a necessidade e com o apoio financeiro obtido pelos pesquisadores do grupo (Figura 1 e 2).

Desta forma o ambiente promove a convivência de professores de graduação e pósgraduação, alunos da graduação dos cursos da Ciência da Computação, Engenharia da Computação, Mecânica, Design e Arquitetura, como também pós-graduandos em nível de mestrado e doutorado, das áreas da Ciência da Computação e Educação.

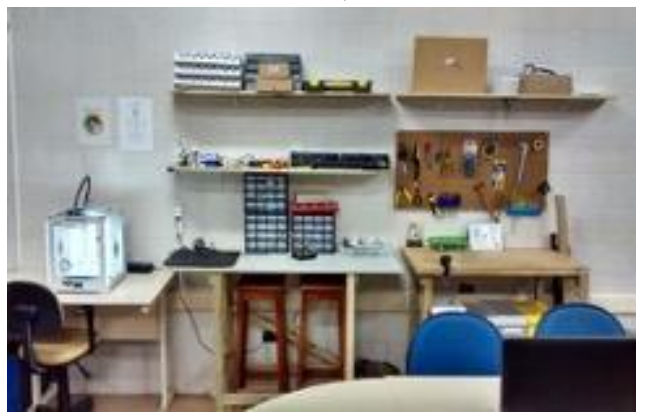

Figura 1 - Algumas das Ferramentas do Lite

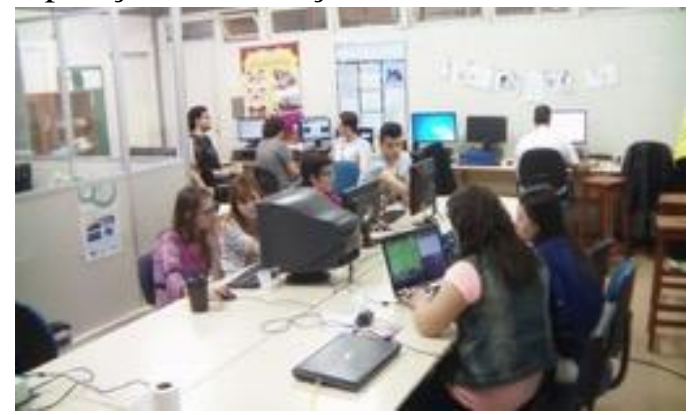

Figura 2 - Computadores e Ambiente físico

O laboratório conduz um projeto de extensão em parceria com uma escola pública municipal. Este projeto busca proporcionar o desenvolvimento do pensamento computacional colocando os estudantes em contato com conceitos e práticas usuais em cursos de computação. Os estudantes aprendem conceitos de lógica de programação, aprendem a construir pequenas aplicações com programação com uso do Portugol Studio (Noschang et al., 2014), aprendem conceitos de eletrônica e sistemas digitais e desenvolvem projetos de robótica com uso de microcontroladores usando Arduíno e linguagem C. O nome do projeto foi eleito pelos seus participantes e é Lite is Cool.

Os alunos que participaram do Lite is Cool foram indicados pela direção da escola Nereu Ramos, totalizando 12 (doze) estudantes, sendo 6 (seis) meninas e 6 (seis) meninos. Junto a esse grupo se uniram mais 2 (dois) alunos de escolas particulares, 1 (um) do ensino médio e outro do $8^{\circ}$ ano do ensino fundamental ambos interessados em participar do projeto como voluntários, tendo participado 14 alunos, 6 (seis) meninas e 8 (oito ) meninos.

Devido a restrição de espaço do laboratório, os estudantes foram separados em duas turmas, Turma 1 ( 8 alunos do 1o ano) e Turma 2 (6 alunos do 20 ano), Os dois estudantes de escolas particulares foram introduzidos na Turma 1. Cada turma participava de dois encontros semanais com 4 horas de duração. 
V Congresso Brasileiro de Informática na Educação (CBIE 2016)

Anais do XXII Workshop de Informática na Escola (WIE 2016)

Do programa de atividades realizado, a última atividade realizada possibilitou aos participantes vivenciarem os preceitos do construcionismo e do movimento maker mais diretamente e serão detalhadas no relato de experiência a seguir. A atividade ocorreu durante cinco semanas consecutivas. Ao final de cada encontro foram registradas as observações mais relevantes e as reflexões dos pesquisadores.

\section{Relato da Experiência}

A atividade teve inicio no mês de novembro de 2015 e o teve seu encerramento com a apresentação dos projetos desenvolvidos na Feira de Ciências da escola paraceira em dezembro de 2015. Os 2 (dois) alunos que não eram alunos regulares dessa escola também puderam participar apresentando seus trabalhos.

$\mathrm{Na}$ primeira semana, os estudantes aprenderam como usar o Arduino. Foi introduzido o conceito do que é o Arduino, explicado como funciona o hardware e a IDE de programação do Arduino, como preparar o Arduino para o início de um projeto e como utilizar os componentes básicos. Ao final desta introdução foi passado um desafio para que os alunos conseguissem ligar um Led (Diodo emissor de luz) através do Arduino. Em sequência os alunos foram desafiados com alguns exercícios extras como:

- Acender dois Leds, desta forma foi estimulado que os estudantes usassem um conhecimento já aprendido anteriormente em relação a circuitos básicos, ligando os Leds de forma paralela ou serial na mesma porta do Arduino;

- Acender dois Leds em tempos diferentes, desta forma foi estimulado que os estudantes utilizassem duas portas para controlar diferentes tempos de funcionamento dos Leds;

- Substituir o Led por um motor de corrente contínua, desta forma foi estimulado que os estudantes entendessem que o Arduino pode funcionar como uma fonte de energia controlável.

No decorrer dessas atividades observou-se que os estudantes da Turma 1 tiveram, inicialmente, maior dificuldade na compreensão de como funciona o Arduino. Esse fato só se evidenciou no primeiro encontro, não influenciando na realização das demais atividades propostas com o objetivo de criar um projeto utilizando o Arduino. Já no primeiro encontro observou-se que os participantes dessa atividade sentiram-se capazes de criar objetos de seus interesses com o Arduino.

$\mathrm{Na}$ segunda semana foi realizada a exploração de projetos no site www.instructables.com. Este ambiente é um repositório de tutoriais de projetos nas mais diversas áreas, sendo muito forte em tutorias que envolvem tecnologia como o Arduino. Exemplos de tutoriais de projetos que inspiraram os estudantes : como usar um sensor de temperatura e sensor de umidade; como manipular um display; como montar um robô que rabisca; como utilizar o Led RGB; como montar Leds em forma de matriz, entre outros tutoriais disponíveis. Esse ambiente promove um fácil entendimento para iniciantes.

O objetivo dessa atividade era que os estudantes explorassem projetos já desenvolvidos, testando na prática os componentes que fossem interessantes para eles e que estimulassem a criatividade para criação de seus próprios projetos. 
V Congresso Brasileiro de Informática na Educação (CBIE 2016)

Anais do XXII Workshop de Informática na Escola (WIE 2016)

Foi interessante essa atividade, pois se observou que os grupos trocavam entre si as informações que obtinham sobre os componentes. O compartilhamento de informação, de colaboração e de interação entre os estudantes evidenciou-se de forma voluntária e positiva. Essa atividade possibilitou que os estudantes conduzissem a investigação e o conhecimento que obtiveram nesse encontro.

A interação com o Instructables instigou a capacidade de pesquisar dos participantes e estimulou o delineamento da ideia central dos projetos, que alguns dos grupos posteriormente desenvolveram. Entre os componentes explorados destacaram-se os sensores de temperatura, umidade e iluminação, os Leds RGB e o servo motor.

$\mathrm{Na}$ terceira e quarta semana os estudantes iniciaram a criação de seus projetos. Nesta etapa nem todos escolheram desenvolver um projeto utilizando o Arduino, porém todos os estudantes participaram ativamente em pelo menos em um projeto que integrava o Arduino. Cada um dos produtos desenvolvidos tinha um estudante responsável, no qual os demais estudantes podiam contribuir com ideias como também participar no desenvolvimento juntamente com o responsável.

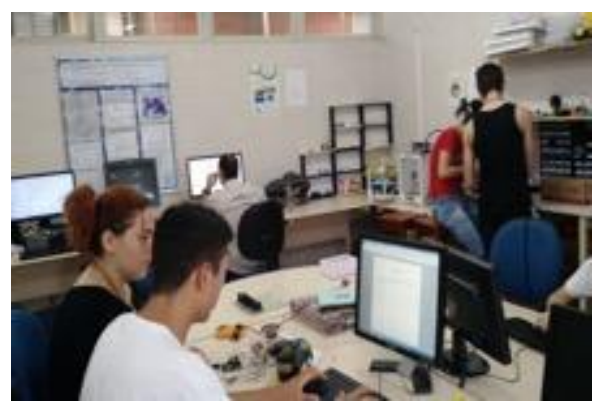

Figura 3 - Criando projetos - I

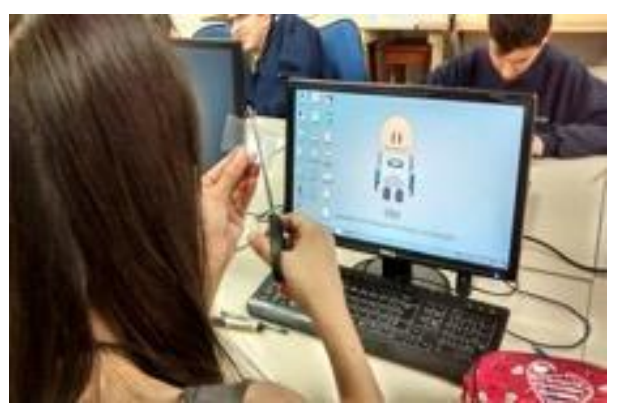

Figura 4 - Criando projetos - II

O projeto "Pikachu Eletrônico" tinha dois estudantes como responsáveis. Foi utilizado uma carcaça impressa na impressora 3D - Ultimaker - do Lite, 2 (dois) servos motor que faziam os movimentos das orelhas e 2 (dois) Leds na cor vermelha que representava as Bochechas do personagem.

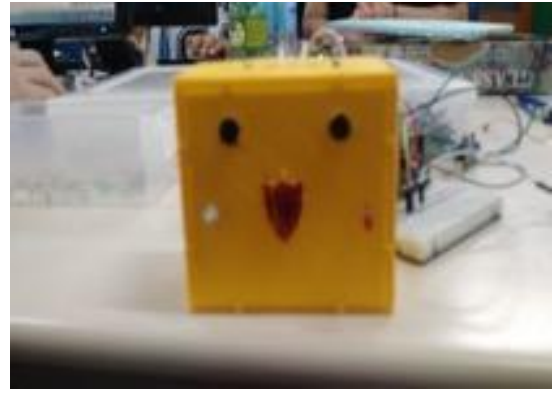

Figura 5 - Desenvolvendo o Pikachu Eletrônico

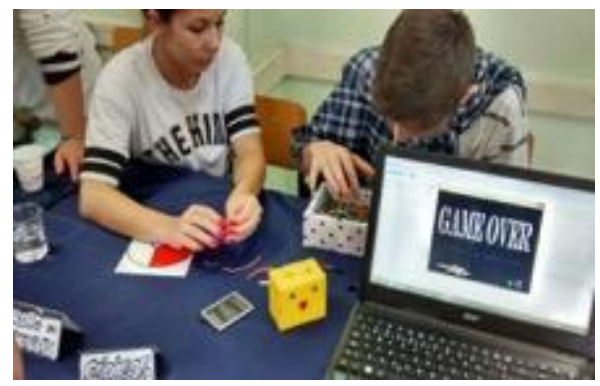

Figura 6 - Pikachu Eletrônico na Feira de Ciência

O projeto "Smart Plant" foi desenvolvido por 3 (três) estudantes responsáveis. Esse projeto foi objetivou a criação de uma estrutura repleta de sensores e um display acoplado a 
V Congresso Brasileiro de Informática na Educação (CBIE 2016)

Anais do XXII Workshop de Informática na Escola (WIE 2016)

uma planta. Os sensores mediam a temperatura, o nível de umidade e o nível de luminosidade na planta, fazendo que fosse possível o display mostrar as necessidades da planta, como água, retirar do sol e a temperatura do local onde se encontra a planta.

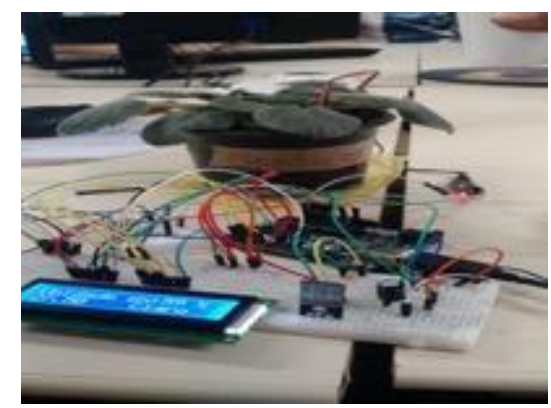

Figura 7 - Desenvolvendo a Smart Plant

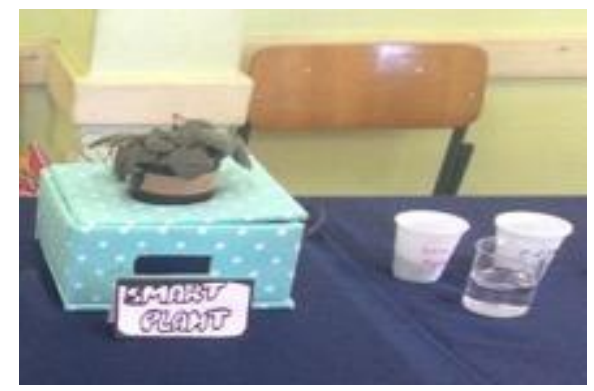

Figura 8 - Smart Plant na Feira de Ciências

O "Semáforo" é um projeto que foi desenvolvido por somente um aluno responsável. Esse projeto simula o funcionamento de um semáforo, utilizando Leds das cores verde, amarelo e vermelho e um Arduino para controlar o tempo.

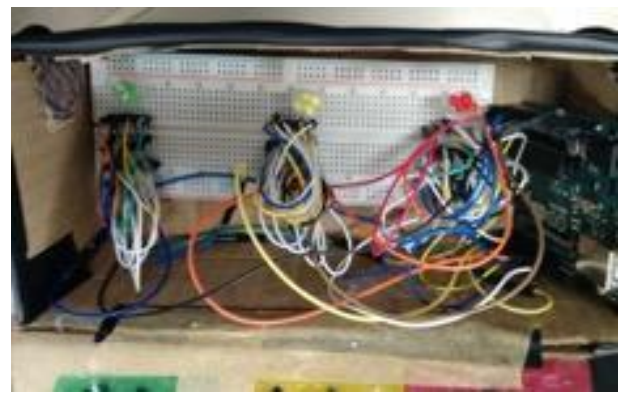

Figura 9 - Desenvolvendo o Semáforo

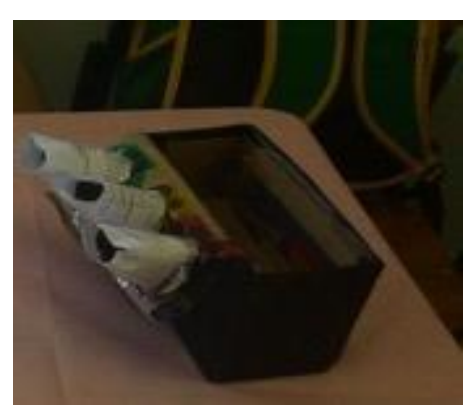

Figura 10- Semáforo na Feira de Ciências

O "Cubo RGB" - é um projeto com um estudante responsável que apresentou interesse nas misturas de cores, desta forma focou em testar como as cores se misturavam com o Led do tipo RGB - Red Green Blue. O estudante montou 3 (três) botões no qual cada botão acionava uma das cores do Led RGB. A estrutura deste projeto foi desenhada por outro estudante que demonstrou muito interesse em desenhos, unimos montaram toda a carcaça do Cubo RGB. Esse projeto não contém o uso do Arduino em sua versão final, pois apesar de ter realizado o teste acionando o Led RGD com o Arduino o estudante achou mais interessante apresentar o trabalho acionando as cores a partir de botões. 
V Congresso Brasileiro de Informática na Educação (CBIE 2016)

Anais do XXII Workshop de Informática na Escola (WIE 2016)

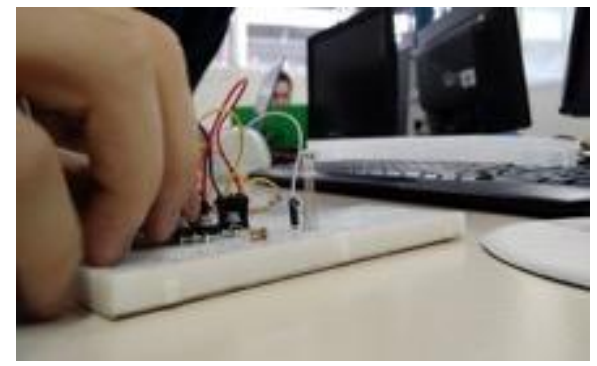

Figura 11- Desenvolvendo o Cubo RGB

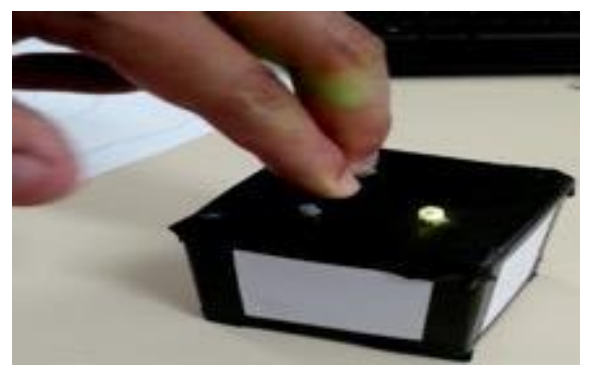

Figura 12 - Cubo RGB em processo de criação

O estudante que apresentou interesse em desenhos desenvolveu outro projeto, porém sendo responsável por ele, que foi o "Fazedor de Círculos". Para este projeto foi utilizado uma base de madeira no qual foi acoplado 3 (três) canetas para fazer as pernas, 1 (um) motor com o peso na ponta, acoplado na base da estrutura. O peso na ponta do motor foi feito com lixo eletrônico. Este estudante integrou diversos projetos como auxiliar nos desenhos e prototipação das estruturas, descobrindo e valorizando seu potencial nessas áreas.

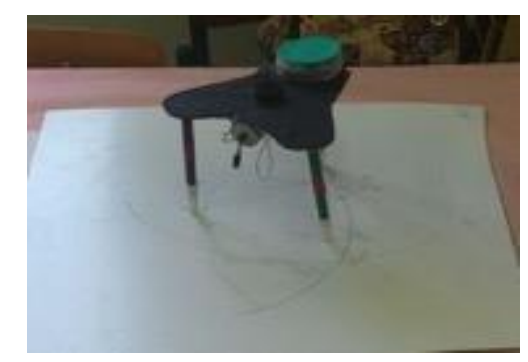

Figura 13 - Fazedor de Círculos na Feira de Ciências

O "Universe Wars" foi criado por somente 1 (um) responsável, que desenvolveu esse jogo usando a ferramenta Portugol Studio ${ }^{1}$. Na criação desse jogo o estudante não usou Arduino, pois no decorrer de todo o projeto Lite is cool ele se identificou muito com atividades de programação e criação de jogos. Fato que não impossibilitou a participação desse estudante em projetos que envolviam Arduino. O "Universe Wars" acontece no espaço e o jogador precisa controlar a nave, desviando dos meteoros. Conforme o tempo passa a velocidade em que os meteoros aparecem aumenta tornando-se um desafio maior para os jogadores. Quando a nave colide com o meteoro o jogo é encerrado e a quantidade de meteoros que a nave conseguiu desviar é demonstrado na tela.

\footnotetext{
${ }^{1}$ Lite.acad.unili.br/category/portugol
} 
V Congresso Brasileiro de Informática na Educação (CBIE 2016)

Anais do XXII Workshop de Informática na Escola (WIE 2016)

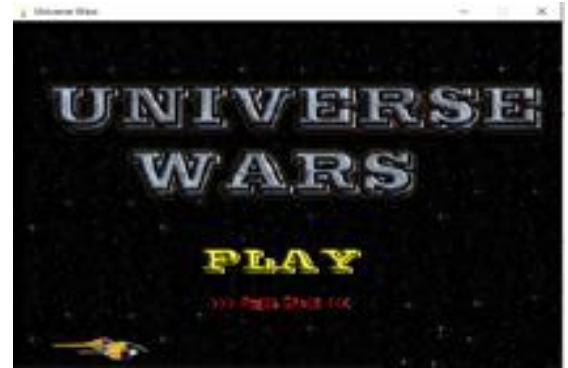

Figura 14 - Tela inicial do Universe Wars

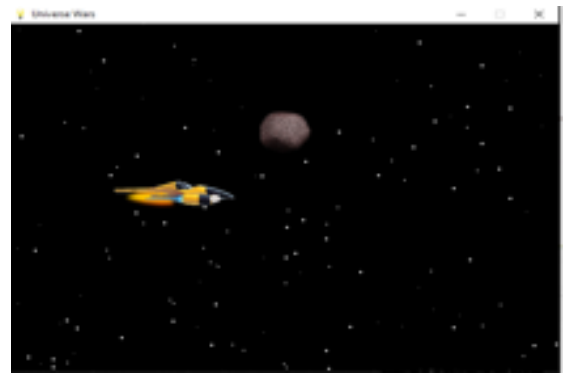

Figura 15 - Tela do Jogo Universe Wars

O projeto "Matriz de Leds" foram desenvolvidos por 2 (dois) estudantes. Apresenta uma matriz de 3 (três) andares no qual os Leds conseguem ser acendidos em grupo ou separadamente, as luzes acendem de acordo com a programação feita no Arduino. Esse projeto envolveu assuntos já aplicados na escola regular e os alunos conseguiram resgatar os conceitos de matriz. Uma forma prática de aplicar conteúdos vistos anteriormente só na teoria.

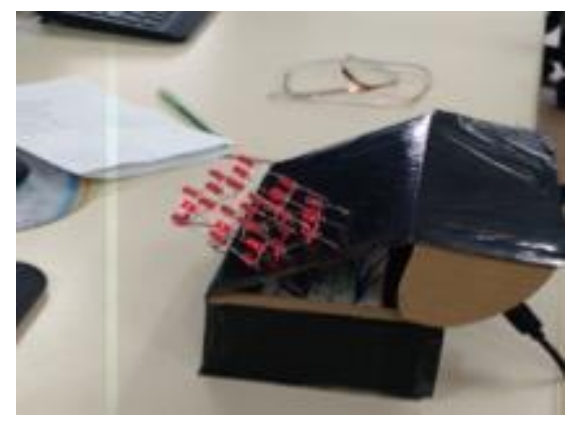

Figura 16 - Desenvolvendo Matriz de Leds

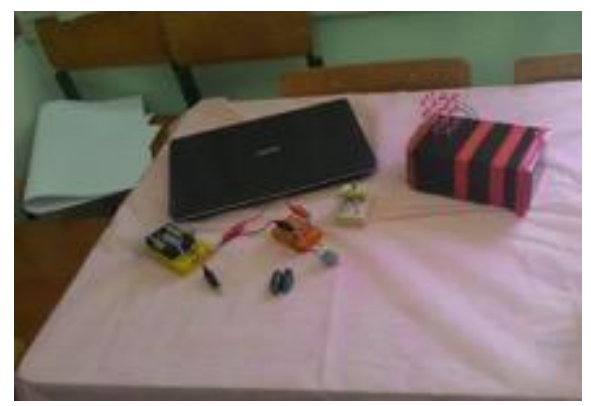

Figura 17 - Matriz de Leds na Feira de Ciências

De forma geral os grupos desenvolveram os trabalhos de forma colaborativa compartilhando informações e opiniões. Com exceção de um estudante que preferiu desenvolver seu projeto sozinho e não apresentou interesse em auxiliar os demais trabalhos. Essa era características marcou a participação desse estudante em todas as atividades desenvolvidas no Lite is Cool.

"Space War", "Cubo RGB" e "Fazedor de Círculos" foram criações que se distanciaram do objetivo de criar tecnologias com o uso do Arduino. Em alguns casos, na opinião dos estudantes, o Arduino não parecia ser a melhor opção para aquele projeto em especifico. Como os trabalhos que estavam em desenvolvimento deveria ser de interesse dos estudantes, não foi estabelecido como critério para o projeto final o uso do Arduino.

Os bolsistas e voluntário do laboratório (Lite), estudantes de cursos de gradução, de diversas áreas de conhecimento como engenharias, ciência da computação, arquitetura e design, foram determinantes para o sucesso dos projetos dos alunos do ensino médio. Os conhecimentos específicos das diversas áreas auxiliaram nas dúvidas e resolução de problemas específicos bem como inspiraram a criatividade dos estudantes. A participação da equipe de desenvolvimento e manutenção do Portugol Studio foi um exemplo bem sucedido no auxilio das atividades de programação e no desenvolvimento do Jogo "Space War" 
Alguns dos trabalhos apresentados na feira de Ciências foram marcados pelas características de seus desenvolvedores. A "Smart Plant" foi motivada a partir do estimulo dos estudantes na participação das aulas de biologia no ensino regular. O "Cubo RGB" foi inspirado a partir do conhecimento que o aluno responsável adquiriu em um curso de edição de imagem, o qual seu interesse era bastante evidente. O "Fazedor de Círculos" foi criado a partir do interesse em desenho do desenvolvedor responsável.

\section{Conclusões}

No decorrer do processo de criação dos projetos os estudantes utilizaram conhecimentos prévios adquiridos em atividades do Lite is Cool. Indicação de que os conteúdos foram assimilados e aproveitados em atividades de seu interesse, estimulando competências já existentes, porém não evidenciadas até o momento.

Não foram evidenciadas diferenças significativas entre os participantes dos gêneros feminino e masculino no envolvimento e na criação dos projetos apresentados na feira de Ciências. Tradicionalmente atividades com robótica voltam-se a construção de projetos mais alinhados com o universo masculino, fato que não ocorreu neste projeto. Ambos os gêneros mostraram-se motivados e construíram projetos de seus interesses. Acredita-se que a liberdade para escolher a temática dos projetos é o principal fator para que isto tenha ocorrido.

As prerrogativas do construcionismo e do movimento Maker se mostraram condizentes com os resultados das atividades desenvolvidas pelos estudantes. Os produtos finais apresentam características que demonstraram o protagonismo de seus desenvolvedores, fato que os deixou orgulhosos e surpresos com o resultado das criações realizadas. Além de motivá-los nos momentos de dificuldades durante o processo de criação.

A abordagem "mão na massa" possibilitou a interação entre os participantes, a cooperação, o compartilhamento de informações e ideias, criando um ambiente positivo que auxiliou no processo de criação. Cada indivíduo além da criação do seu projeto conseguiu auxiliar outras equipes, valorizando suas habilidades mais acentuadas. Em alguns relatos dos alunos no final das atividades realizadas em 2015 os estudantes demonstraram que criaram uma relação de colaboração pessoal entre eles em outros contextos.

A presença de um ambiente repleto de tecnologias com integrantes, de pósgraduação e ensino superior, que conhecem diversas áreas do conhecimento e dominam essas tecnologias, estimulou os desenvolvedores dos projetos a não imporem limites à criação, tanto para estudantes de escolas públicas quanto para os de escolas privadas. Fato que despertou a criatividade e possibilitou explorar suas habilidades inventivas $\mathrm{e}$ produtivas, tornando-os protagonistas na resolução de problemas e no do desenvolvimento do seu próprio conhecimento. Características que estão presentes e são marcantes em ambientes construcionistas.

Espera-se que atividades como esta relatada neste artigo possam servir de inspiração sobre como proporcionar o desenvolvimento do pensamento computacional em atividades maker que seguem pressupostos construcionistas. Muitos conceitos escolares podem ser trabalhados nesta perspectiva facilitando com que os estudantes percebam a importância dos conceitos, uma vez que utilizam nos para construir algo concreto. 
V Congresso Brasileiro de Informática na Educação (CBIE 2016)

Anais do XXII Workshop de Informática na Escola (WIE 2016)

\section{Referências}

Blikstein, P. Digital fabrication and 'making'in education: The democratization of invention. FabLabs: Of machines, makers and inventors", p. 1-21, 2013.

You cannot think about think ing without think ing about what Seymour Papert would think. 2009.

2008.

O pensamento computacional e a reinvenção do computador na educação.

BOMBASAR, James; SANTIAGO, Rafael; MIRANDA, Elisangela M.; RAABE, André L. A. Ferramentas para o Ensino-Aprendizagem do Pensamento Computacional: onde está Alan Turing?. In: Anais do Simpósio Brasileiro de Informática na Educação. 2015. p. 81.

Milne, A.; Riecke, B.; Antle, A. Exploring Maker Practice: Common Attitudes, Habits and Skills from Vancouver's Maker Community. Studies, v. 19, n. 21, 2014. p. 23.

NATIONAL RESEARCH COUNCIL (NRC). Report of a Workshop on the Scope and Nature of Computational Thinking. National Academies Press, 2010.

Papert, S. Mindstorms: Children, computers and powerful ideas. Basic Books, inc. Artes Médicas: Porto Alegre. 1980.

Santana, A. L. M. Análise do Processo de Montagem de um Brinquedo de Programar: identificação de padrões de aprendizagem em tarefas de engenharia. Dissertação (Mestrado em Computação Aplicada) - Universidade do Vale do Itajaí, 2015. 